\title{
Feeding traces attributable to juvenile Tyrannosaurus rex offer insight into ontogenetic dietary trends
}

\author{
Joseph E Peterson ${ }^{\text {Corresp., }}{ }^{1}$, Karsen N Daus ${ }^{1}$ \\ ${ }^{1}$ Department of Geology, University of Wisconsin Oshkosh, Oshkosh, Wisconsin, United States of America \\ Corresponding Author: Joseph E Peterson \\ Email address: petersoj@uwosh.edu
}

Theropod dinosaur feeding traces and tooth marks yield paleobiological and paleoecological implications for social interactions, feeding behaviors, and direct evidence of cannibalism and attempted predation. However, ascertaining the taxonomic origin of a tooth mark is largely dependent on both the known regional biostratigraphy and the ontogenetic stage of the taxon. Currently, most recorded theropod feeding traces and bite marks are attributed to adult theropods, whereas juvenile and subadult tooth marks have been rarely reported in the literature. Here we describe feeding traces attributable to a late-stage juvenile Tyrannosaurus rex on a caudal vertebra of a hadrosaurid dinosaur. The dimensions and spacing of the traces were compared to the dentition of Tyrannosaurus rex maxillae and dentaries of different ontogenetic stages. These comparisons reveal that the tooth marks present on the vertebra closely match the maxillary teeth of a late-stage juvenile Tyrannosaurus rex specimen histologically determined to be 11-12 years of age. These results demonstrate that late-stage juvenile and subadult tyrannosaurs were already utilizing the same large-bodied food sources as adults despite lacking the bonecrushing abilities of adults. Further identification of tyrannosaur feeding traces coupled with experimental studies of the biomechanics of tyrannosaur bite forces from younger ontogenetic stages may reveal dynamic dietary trends and ecological roles of Tyrannosaurus rex throughout ontogeny. 
1 Feeding traces attributable to juvenile Tyrannosaurus

2 rex offer insight into ontogenetic dietary trends

3

4

5

6

7

8

9

10

11

12

13

14

15

16

17

18

19

20

21

22

23

24

25

26

27

28

29

30

31

32

33

34

35

36

37

38

39

Joseph E. Peterson, and Karsen N. Daus

${ }^{1}$ Department of Geology, University of Wisconsin Oshkosh, Oshkosh, WI, USA

Corresponding Author:

Joseph E. Peterson

Department of Geology, University of Wisconsin Oshkosh, 800 Algoma Blvd, Oshkosh, WI, 54901, USA

Email address: petersoj@uwosh.edu

\section{Abstract}

Theropod dinosaur feeding traces and tooth marks yield paleobiological and paleoecological implications for social interactions, feeding behaviors, and direct evidence of cannibalism and attempted predation. However, ascertaining the taxonomic origin of a tooth mark is largely dependent on both the known regional biostratigraphy and the ontogenetic stage of the taxon. Currently, most recorded theropod feeding traces and bite marks are attributed to adult theropods, whereas juvenile and subadult tooth marks have been rarely reported in the literature. Here we describe feeding traces attributable to a late-stage juvenile Tyrannosaurus rex on a caudal vertebra of a hadrosaurid dinosaur. The dimensions and spacing of the traces were compared to the dentition of Tyrannosaurus rex maxillae and dentaries of different ontogenetic stages. These comparisons reveal that the tooth marks present on the vertebra closely match the maxillary teeth of a late-stage juvenile Tyrannosaurus rex specimen histologically determined to be 11-12 years of age. These results demonstrate that late-stage juvenile and subadult tyrannosaurs were already utilizing the same large-bodied food sources as adults despite lacking the bone-crushing abilities of adults. Further identification of tyrannosaur feeding traces coupled with experimental studies of the biomechanics of tyrannosaur bite forces from younger ontogenetic stages may reveal dynamic dietary trends and ecological roles of Tyrannosaurus rex throughout ontogeny.

\section{Introduction}

Bite marks and feeding traces attributable to theropods dinosaurs provide important insight on behavior, physiology, and paleobiology. Furthermore, bite and feeding traces on fossilized bone represents a valuable demonstration of paleoecology; the interaction between two organisms as preserved in both traces and body fossils. Bite marks and feeding traces are relatively common in the fossil record, and are widely reported for theropod dinosaurs. Such traces have provided evidence of gregariousness and social interactions (Tanke and Currie, 1998; 
40 Bell and Currie, 2009; Peterson et al., 2009; Currie and Eberth, 2010), feeding behaviors and 41 bone utilization (Erickson and Olson, 1996; Chure et al., 1998; Hone and Watabe, 2010; Hone DePalma et al., 2013), and cannibalism (Longrich et al., 2010; McLain et al., 2018).

Despite the abundant record of theropod tooth marks, ascertaining the origins of feeding traces and bite marks can be challenging; determining the species responsible for the marks and establishing whether tooth marks are the result of active predation or scavenging largely depends on the taphonomic setting of the skeletal elements, the presence of shed teeth, and the location of the traces on the specimen in question (Hunt et al, 1994; Bell and Currie, 2009; Hone and Rauhut, 2010). However, most recorded cases of theropod feeding or the presence of bite marks are attributed to adult theropods, leaving the presence of juvenile and subadult tooth marks largely absent from the literature and discussion.

Here we report on the presence of feeding traces on the caudal vertebra of a hadrosaurid dinosaur (BMR P2007.4.1, "Constantine"). Based on the shape and orientation of the traces, and the known fauna of the Hell Creek Formation, they are interpreted to be feeding traces of a large theropod dinosaur, such as Tyrannosaurus rex (Erickson and Olson, 1996; Horner et al., 2011). By comparing the dimensions and spacing of the traces with the maxillae and dentaries of specimens of Tyrannosaurus rex of different ontogenetic stages, we interpret these tooth marks to be feeding traces from a juvenile Tyrannosaurus rex and discuss the insights the specimen provides for juvenile tyrannosaur feeding behavior.

Institutional Abbreviations - BHI, Black Hills Institute of Geologic Research, Hill City, SD, USA; BMR, Burpee Museum of Natural History, Rockford, IL, USA.

\section{Geologic Setting}

Specimen BMR P2007.4.1 ("Constantine") is a partial hadrosaurid skeleton collected from the Upper Cretaceous Hell Creek Formation of Carter County, southeastern Montana in the Powder River Basin (Figure 1). This specimen was collected on public lands under BLM Permit \#M96842-2007 issued to Northern Illinois University and is accessioned at the Burpee Museum of Natural History in Rockford, IL. Exact coordinates for the location are on file in the paleontology collections at the Burpee Museum of Natural History (BMR), where the specimen is reposited.

The collection locality is composed of a $4 \mathrm{~m}$ fine-grained, gray-tan lenticular sandstone within a larger surrounding blocky mudstone unit (Figure 2). The sandstone lacks bedforms, resulting from either a) rapid accumulation (resulting in a lack of sedimentary structures), or b) sedimentary structures that were obliterated by later currents or bioturbation, and is rich in rounded and weathered microvertebrate remains. The site is stratigraphically positioned approximately $44 \mathrm{~m}$ above the underlying Fox Hills - Hell Creek contact and overlies $0.5 \mathrm{~m}$ of siderite, which sits above a $5 \mathrm{~m}$ blocky mudstone. Grains are subrounded to subangular. Microvertebrate and fragmented macrovertebrate fossils are abundant and heavily rounded and abraded (Peterson et al., 2011). The fine-grained composition suggests a channel-fill deposit, 
80

81

82

83

84

85

86

87

88

89

90

91

92

93

94

95

96

97

98

99

100

101

102

103

104

105

106

107

108

109

110

111

112

113

114

115

116

117

118

119

overlying a floodplain deposit (Murphey et al., 2002; Peterson et al., 2011). The taphonomic distribution of the elements and their stratigraphic position suggests the skeleton was subaerially exposed on a floodplain for a considerable period of time prior to burial, allowing for weathering, disarticulation, and removal of many skeletal elements.

\section{Materials \& Methods}

Specimen BMR P2007.4.1 ("Constantine") consists of weathered pelvic elements (sacrum, left and right ilia), three dorsal vertebrae, and two proximal caudal vertebrae (Figure 3, Table 1). The dorsal vertebrae were too weathered for collection, though their dimensions and relative locations within the quarry assemblage were measured and documented. Additionally, a series of heavily-weathered bone fragments and a small shed theropod tooth (Saurornithoides $s p$.) were also collected.

The ilium of BMR P2007.4.1 possesses a number of hadrosaurid characters such as 1) a shallow morphology, 2) a $\sim 23^{\circ}$ preacetabular process in medial view relative to the main body, and 3) a well-developed supra-acetabular process caudal to the acetabulum. While these characters are common among hadrosaurids, the stratigraphic position of BMR P2007.4.1 suggests it is attributable to the Late Cretaceous hadrosaurid Edmontosaurus (i.e. Brett-Surman and Wagner, 2007; Campione, 2014).

The centra of the two caudal vertebrae lack any evidence for hemal arch attachments, suggesting they are among the more cranial-positioned caudal vertebrae, such as $\mathrm{C} 1-\mathrm{C} 4$ (Campione, 2014). One of the caudal vertebrae possesses three $v$-shaped indentations on the ventral surface of the centrum (Figure 4A-E; Supplemental Figures S1, S2). These traces feature collapsed cortical bone within the indentation, producing puncture marks (sensu Bindford, 1981). The punctures penetrate $5 \mathrm{~mm}$ deep, are spaced $68 \mathrm{~mm}$ apart from their apical centers, show no signs of healing, and are inferred to have been created postmortem as feeding traces (e.g. Noto et al., 2012; Hone and Tanke, 2015; McLain et al., 2018). The v-shape preserved in each puncture indicates that the original teeth would have possessed a prominent keel, though no striations from serration marks are present in the traces (sensu D'Amore and Blumenschine, 2009).

The large size and shape of the punctures suggests that they were produced by a large- to medium-bodied carnivore. Such carnivores from the Hell Creek Formation include tyrannosaurs such as Tyrannosaurus rex (Erickson and Olson, 1996; Horner et al., 2011), medium-sized dromaeosaurids such as Dakotaraptor steini (DePalma et al., 2015), and crocodylians such as Borealosuchus sternbergii, Brachychampsa montana, and Thoracosaurus neocesariensis (Matsumoto and Evans, 2010). By comparing the shape and orientation of the traces to the teeth of these carnivores from the Hell Creek Formation, they are hypothesized to be bite marks from a large theropod dinosaur, such as Tyrannosaurus rex (Erickson and Olson, 1996); crocodylian teeth are circular in cross-section and too small, and dromaeosaurid teeth - even large dromaeosaurids such as D. steini - are too small and laterally-compressed to have produced the punctures observed on BMRP2007.4.1. 
120

121

122

123

124

125

126

127

128

129

130

131

132

133

134

135

136

137

138

139

140

141

142

143

144

145

146

147

148

149

150

151

152

153

154

155

156

157

158

To test this hypothesis, the punctures on the caudal vertebra of BMR P2007.4.1 were first coated in Rebound ${ }^{\mathrm{TM}} 25$ platinum-cure silicone rubber (Smooth-On) in order to make a silicone peel of the punctures in order to better visualize the morphology and dimensions of the teeth responsible for the traces (Figure 5A-B; Supplemental Figures S3, S4). These "teeth" were then compared with the dental dimensions and spacing of two Tyrannosaurus maxillae and dentaries. To approximate the ontogenetic stage of the tyrannosaur, a late-stage juvenile specimen (BMR P2002.4.1, "Jane") histologically determined to be approximately 11-12 years old at the time of death (Erickson et al., 2006) that possesses laterally compressed, sharp crowns, and a mature specimen (BHI 3033, "Stan") with robust, blunt crowns were utilized.

All specimens were digitized via triangulated laser texture scanning with a NextEngine 3D Laser Scanner, capturing data at seven scanning divisions in high-definition (2.0k points/in2). The resulting digital models were built with the NextEngine ScanStudio HD Pro version 2.02, and finalized as STL models (Supplemental Figures S1-S8). Scanning was conducted at the Department of Geology at the University of Wisconsin-Oshkosh in Oshkosh, WI.

The tooth spacing of both adult and late-stage juvenile tyrannosaur maxillae and dentaries were measured for both immediately-adjacent teeth and teeth from alternating replacement positions (i.e. Zahnreihen), and compared with the spacing of the punctures (Figure 6A-B), similar to Fahlke's (2012) investigation of likely Basilosaurus bite marks on specimens the smaller whale Dorudon. Furthermore, the cross-sectional morphology of adult and late-stage juvenile tyrannosaur maxillae and dentaries were measured labiolingually and mesiodistally at a $5 \mathrm{~mm}$ apical depth for each tooth crown, and plotted with measurements from the punctures found on BMR P2007.4.1 (Figure 7).

\section{Results}

The mesiodistal width measurements from the silicone peel taken from BMR P2007.4.1 average $7.8 \mathrm{~mm}$ and the labiolingual depth average was $5.2 \mathrm{~mm}$. Maxillary and dentary teeth of the adult Tyrannosaurus (BHI 3033) were found to be too large and widely spaced to have produced the punctures (Figures 7,8A,B; Supplemental Figures S4, S5; Table 2A-C). For BHI 3033, the average dentary tooth crown mesiodistal width at $5 \mathrm{~mm}$ depth was $7.13 \mathrm{~mm}$, and the average dentary tooth crown labiolingual depth at $5 \mathrm{~mm}$ was $4.10 \mathrm{~mm}$. The average maxillary crown mesiodistal width at $5 \mathrm{~mm}$ were $7.72 \mathrm{~mm}$, and the average maxillary crown labiolingual depth at $5 \mathrm{~mm}$ averaged to $4.21 \mathrm{~mm}$.

However, the teeth of BMR P2002.4.1 produced similarly shaped punctures at $5 \mathrm{~mm}$ apical depth (Figures 7, 9; Supplemental Figures S7, S8; Table 2B-C). The puncture measurements taken from the peel, BMR P2007.4.1 demonstrate a mesiodistal width and labiolingual depth consistent with the measurements taken from the maxillary and dentary teeth of the late-stage juvenile Tyrannosaurus. When plotted against the mesiodistal width and labiolingual depth of the maxillary teeth, measurements from the peel taken from BMR P2007.4.1 fall well within the cluster radius created by the late-stage juvenile Tyrannosaurus, 
159 BMR P2002.4.1 (Figure 7). Furthermore, the inferred crown spacing of the punctures closely

160

161

162

163

164

165

166

167

168

169

170

171

172

173

174

175

176

177

178

179

180

181

182

183

184

185

186

187

188

189

190

191

192

193

194

195

196

197

198

matched those of the late-stage juvenile tyrannosaur maxilla (Table 3A-B).

\section{Discussion and Conclusions}

While feeding traces and bite marks attributed to mature tyrannosaurids are welldocumented in common Late Cretaceous taxa such as hadrosaurids and ceratopsians (i.e. Fiorillo, 1991; Erickson et al., 1996a,b; Jacobsen, 1998; Farlow and Holtz, 2002; Fowler and Sullivan, 2006; Peterson et al., 2009; Bell and Currie, 2010; Fowler et al., 2012; DePalma et al., 2013, Mclain et al., 2018), the identification of juvenile tyrannosaur feeding traces adds insight into the role of juvenile theropods in Cretaceous ecosystems. The dimensions and spacing of the punctures closely matches the maxillary teeth of BMR P2002.4.1, a late-stage juvenile (11-12 yr old) tyrannosaur which incidentally itself possesses morphologically similar craniofacial lesions previously interpreted as a conspecific bite (Peterson et al., 2009).

Longrich et al. (2010) reported on evidence of cannibalism in T. rex based on a number of bitten and scored remains of Tyrannosaurus rex, some attributed to juvenile or subadult individuals. However, many of these traces resemble the 'puncture and pull' bite marks that have previously been attributed to T. rex (Erickson et al., 1996a; Erickson et al., 1996b), and also include furrows and scores (sensu Binford, 1981).

Correlating traces in bone, such as tooth marks, to specific taxa and ontogenetic stages usually requires direct comparisons (e.g. Peterson et al., 2009; Fahlke, 2012). However, in cases where direct comparisons are not available, estimates can be made for tooth size, morphology, and spacing based on ontogenetic trajectories. While bite marks and feeding traces attributable to younger juvenile and hatchling tyrannosaurs have not yet been identified, the punctures present on the caudal vertebra of BMR P2007.4.1 provide direct evidence that late-stage juvenile Tyrannosaurus rex such as BMR P2002.4.1 possessed - at least in part - a similar diet as adults.

While bite marks resulting from active predation cannot easily be distinguished from postmortem feeding traces, the ventral position of the punctures in the caudal centrum of BMR P2007.4.1 suggests that the feeding was taking place postmortem with the hadrosaur already on its side (Chure et al., 1996). The afflicted vertebra is from the cranial-most part of the tail.

Observations of the feeding behaviors of carnivoran mammals and birds indicate that in most cases, consumption of the axial skeleton occurs after limbs and viscera have been consumed (e.g. Hill and Behrensmeyer, 1980; Haglund, 1997; Carson et al., 2000; and Behrensmeyer et al., 2003). Hadrosaur tails had substantial muscles such as $\mathrm{m}$. ilio-ischocaudalis and $\mathrm{m}$.

caudofemoralis longus (Persons and Currie, 2014) that might be a target of early stage consumption. However, the ventral bite traces on BMR P2007.4.1 suggest that the tyrannosaur was feeding after the haemal complexes and most of the superficial hypaxial muscles and $\mathrm{m}$. caudofemoralis longus had been removed. As such the punctures on BMR P2007.4.1 suggest later-stage carcass consumption and postmortem feeding behaviors.

The identification of penetrating bite marks attributable to not only Tyrannosaurus rex, but an individual of 11-12 years of age can potentially allow for the determination of the 
199

200

201

202

203

204

205

206

207

208

209

210

211

212

213

214

215

216

217

218

219

220

221

222

223

224

225

226

227

228

229

230

231

232

233

234

235

236

237

238

ontogeny of bite force in Tyrannosaurus rex and for comparison with other theropods (e.g. Barrett and Rayfield, 2006, Gignac et al., 2010; Bates and Falkingham, 2012). Studies on the estimated bite forces of an adult Tyrannosaurus rex have yielded a wide range of results.

Estimates based on muscle volume proposed bite forces between 8,526-34,522 N, coupled with tooth pressures of $718-2,974 \mathrm{MPa}$, and a unique tooth morphology and arrangement to promote fine fragmentation of bone during osteophagy (Gignac and Erickson, 2017). However, estimates incorporating likely muscle fiber length produced results over $64,000 \mathrm{~N}$ for adult $T$. rex (Bates and Falkingham, 2018). Juvenile T. rex such as BMR P2002.4.1 have much narrower and bladelike tooth morphologies and were unlikely to have been able to withstand similar bite forces at this ontogenetic stage. Bates and Falkingham (2012) estimated a maximum bite force for BMR P2002.4.1 at 2,400-3,850 N, and hypothesized that an increase in bite force during growth could indicate a change in feeding behavior and dietary partitioning while approaching adulthood.

Observations on extant crocodylians have documented a wide variety of dietary partitioning during ontogeny (e.g. Tucker et al., 1996; Platt et al., 2006; Platt et al., 2013). In the American crocodile (Crocodylus acutus), hatchling and small juveniles have a dietary overlap of over $80 \%$, commonly feeding upon insects and crustaceans (Platt et al., 2013). Alternatively, larger juveniles, subadults, and adults possess a dietary overlap of over $75 \%$, consisting of more birds, mammals, fish, and other reptiles (Platt et al., 2013). Comparable ontogenetic dietary partitions were also observed in Morelet's crocodile (Crocodylus moreletii) (Platt et al., 2006), and in Australian freshwater crocodiles (Crocodylus johnstoni) (Tucker et al., 1996). However, crocodylians are less discriminant of food sources when scavenging (e.g. Antunes, 2017). While the punctures present on BMR P2007.4.1 are likely from postmortem scavenging behaviors of a juvenile tyrannosaur, the degree of dietary overlap or partitioning between juvenile and adult tyrannosaurs remains unresolved.

Despite not yet possessing the same feeding mechanisms of an adult Tyrannosaurus rex (i.e. bone-crushing and osteophagy), the punctures present on BMR P2007.4.1 demonstrate that late-stage juvenile and subadult tyrannosaurs were already biomechanically capable of puncturing bone during feeding, and were doing so without the large, blunt dental crowns of adults. Further identification of tyrannosaur feeding traces from different ontogenetic stages coupled with experimental studies of the biomechanics of tyrannosaur bite forces may reveal more insight into dynamic dietary trends and ecological role of Tyrannosaurus rex throughout ontogeny.

\section{Acknowledgements}

We wish to thank the 2007 Northern Illinois University field crew for assistance in the excavation of the BMR P2007.4.1, including Samuel Adams, Ryan Hayes, Erik Gulbrandsen, and David Vaccaro. We wish to offer particular appreciation to the Northern Illinois University students Christina Constantine-Laughlin and the late Dan Bocklund, who first discovered the specimen and to whom this study is dedicated. We also thank Kelsey Marie Kurz for assistance with specimen preparation. We thank Josh Matthews and Scott Williams of the Burpee Museum 
239

240

241

242

243

244

245

246

247

248

249

250

251

252

253

254

255

256

257

258

259

260

261

262

263

264

265

266

267

268

269

270

271

272

273

274

275

276

of Natural History for access to specimens, and Doug Melton of the Miles City, MT Bureau of Land Management office for assistance with permitting. We thank Jonathan Warnock for providing valuable feedback from early versions of the manuscript. We also that John R. Hutchinson for editing the manuscript, and Stephanie Drumheller-Horton and Eric Snively for offering constructive reviews. Finally, we are grateful to the University of Wisconsin Oshkosh for recognition of this research at the 2018 UW Oshkosh Celebration of Scholarship Symposium.

\section{References}

Antunes M.T. 2017. Huge Miocene crocodilians from western Europe: predation, comparisons with the "False Gharial" and Size. Anuário do Instituto de Geociências 40(3):117-130.

http://dx.doi.org/10.11137/2017 $3 \quad 117 \quad 130$

Barrett P.M. and Rayfield E.J. 2006. Ecological and evolutionary implications of dinosaur feeding behavior. TRENDS in Ecology and Evolution, 21(4):217-224.

Bates K.T. and Falkingham P.L. 2012. Estimating maximum bite force in Tyrannosaurus rex using multi-body dynamics. Biology Letters 8:660-664.

Bates K.T. and Falkingham P.L. 2018. The importance of muscle architecture in biomechanical reconstructures of extinct animals: a case study using Tyrannosaurus rex. Journal of Anatomy 233:635-635.

Behrensmeyer, A.K., C.T. Stayton, and R.E. Chapman. 2003. Taphonomy and ecology of modern avifaunal remains from Amboseli Park, Kenya. Paleobiology 29(1):52-70.

Bell P.R. and Currie P.J. 2009. A tyrannosaur jaw bitten by a confamilial: scavenging or fatal agonism? Lethaia 43(2):278-281.

Binford L.R. 1981. Bones: Ancient Men and Modern Myths: Academic Press, New York, 320p.

Brett-Surman M.K. and Wagner J.R. 2007. Discussion of character analysis of the appendicular anatomy of Campanian and Maastrichtian North American hadrosaurids - variation and ontogeny. In: K. Carpenter (Ed.), Horns and Beaks - Ceratopsian and Ornithopod Dinosaurs, pp. 135-169. Indiana University Press. 
277 Campione N.E. 2014. Postcranial anatomy of Edmontosaurus regalis (Hadrosauridae) from the

278 Horseshoe Canyon Formation, Alberta, Canada. In: D.A. Ebert and D.E. Evans (Eds.),

279 Hadrosaurs, pp. 208-244. Indiana University Press, Bloomington and Indianapolis.

280

281

282

283 Carson, E.A., Stefan V.H., and Powell J.F.. 2000. Skeletal manifestations of bear scavenging.

284 Journal of Forensic Sciences 45(3):515-526.

285

286

Chure D.J., Fiorillo A.R., and Jacobsen A. 1998. Prey bone utilization by predatory dinosaur sin

287 the Late Jurassic of North America, with comments on prey bone use by dinosaurs throughout

288 the Mesozoic. Gaia 15:227-232.

289

290

291

Currie P.J. and Eberth D.A. 2010. Stratigraphy, sedimentology, and taphonomy of the

292

293

294 Albertosaurus bonebed (upper Horseshoe Canyon Formation: Maastrichtian), southern Alberta, Canada. Canadian Journal of Earth Sciences 47(9):1119-1143.

295

D'Amore, D.C. and R.J. Blumensehine. 2009. Komodo monitor (Varanus komodoensis) feeding

296 behavior and dental function reflected through tooth marks on bone surfaces, and the application to ziphodont paleobiology. Paleobiology 35(4): 525-552.

297

298

DePalma R.A., Burnham D.A., Martin L.D., Rothschild B.M., and Larson P.L. 2013. Physical

299 evidence of predatory behavior in Tyrannosaurus rex. Proceedings of the National Academy of

300 Sciences 110(31):12560-12564.

301

302

DePalma R.A., Burnham, D.A., Martin L.D., Larson P.T., and Bakker R.T. 2015. The first giant 303 raptor (Theropoda: Dromaeosauridae) from the Hell Creek Formation. Paleontological

304 Contributions, 14. doi:10.17161/paleo.1808.18764.

305

306

Erickson G.M., Van Kirk S.D., Su J., Levenston M.E., Caler W.E., and Carter, D.R. 1996a. Bite307 308 force estimation for Tyrannosaurus rex from tooth-marked bones. Nature 382:706-708.

310

Erickson G.M. and Olson K.H. 1996b. Bite marks attributable to Tyrannosaurus rex: a

311

312 Erickson G.M., Currie P.J., Inouye B.D., and Winn A.A. 2006. Tyrannosaur life tables: An 313 example of nonavian dinosaur population biology. Science 313:213-217. 
315 Fahlke J.M. 2012. Bite marks revisited - evidence for middle-to-late Eocene Basilosaurus isis 316 predation on Dorudon atrox (both Cetacea, Basilosauridae). Palaeontologica Electronica 15(3), 317 32A, 16p. palaeo-electronica.org/content/2012-issue-3-articles/339-archaeocete-predation.

318

319

320

321

322

323

324

325

326

327

328

329

330

331

332

333

334

335

336

337

338

339

340

341

342

343

344

345

346

347

348

349

350

351

352

353

354

Fiorillo A.R. 1991. Prey bone utilization by predatory dinosaurs. Palaeogeography, Palaeoclimatology, Palaeoecology 88(3-4):157-166.

Farlow J.O. and Holtz T.R. 2002. The fossil record of predation in dinosaurs. In: M. Kowalewski and P.H. Kelley (Eds.), The Fossil Record of Predation. Paleontological Society Paper 8, pp. 251-265.

Fowler D.W., Scannella J.B., Goodwin M.B., and Horner J.R. 2012. How to eat a Triceratops: large sample sample of toothmarks provides new insight into the feeding behavior of Tyrannosaurus. Journal of Vertebrate Paleontology, 32:S96A.

Fowler D.W. and Sullivan R.M. 2006. A ceratopsid pelvis with toothmarks from the Upper Cretaceous Kirtland Formation, New Mexico: evidence of late Campanian tyrannosaurid feeding behavior. New Mexico Museum of Natural History and Science Bulletin 35:127-130.

Gignac P.M., Makovicky P.J., Erickson G.M., and Walsh R.P. 2010. A description of Deinonychus antirrhopus bite marks and estimates of bite force using tooth indentation simulations. Journal of Vertebrate Paleontology, 30(4):1169-1177.

Gignac P.M. and Erikson G.M. 2017. The biomechanics behind extreme osteophagy in Tyrannosaurus rex. Scientific Reports 7(2012). doi.org/10.1038/s41598-017-02161-w.

Haglund W.D. 1997. Dogs and coyotes: postermorem involvement with human remains. In: W.D. Haglund and M.H. Sorg (Eds.), Forensic Taphonomy. pp. 367-382. Boca Raton, FL: CRC Press.

Happ J.W. 2008. An analysis of predatory behavior in a head-to-head encounter between Tyrannosaurus rex and Triceratops. In K. Carpenter and P. Larson(Eds.), Tyrannosaurus rex the Tyrant King, pp. 355-368. Indiana University Press, Bloomington and Indianapolis.

Hill A.P. 1980. Early postmortem damage to the remains of some contemporary East African mammals. In: A.K. Behrensmeyer and A.P. Hill (Eds.), Fossils in the Making. Vertebrate Taphonomy and Paleoecology, pp.131-152. University of Chicago Press, Chicago 60637.

Hone D.W.E. and Watabe M. 2010. New information on the feeding behavior of tyrannosaurs. Acta Palaeontologica Polonica 55:627-634. 
355 Hone D.W.E. and Rauhut O.W.M. 2010. Feeding behaviour and bone utilisation by theropod 356 dinosaurs. Lethia 43:232-244.

357

358

359

360

361

362

363

364

365

366

367

368

369

370

371

372

373

374

375

376

377

378

379

380

381

382

383

384

385

386

387

388

389

390

391

392

Hone D.W.E. and Tanke D.H. 2015. Pre- and postmortem tyrannosaurid bite marks on the remains of Daspletosaurus (Tyrannosaurinae: Therpoda) from Dinosaur Provincial Park, Alberta, Canada. PeerJ 3:e885; DOI 10.7717/peerj.885.

Horner J.R., Goodwin M.B., and Myhrvold N. 2011. Dinosaur census reveals abundant Tyrannosaurus and rare ontogenetic stages in the Upper Cretaceous Hell Creek Formation (Maastrichtian), Montana, USA. PLoS ONE 6(2): e16574.

https://doi.org/10.1371/journal.pone.0016574

Hunt A.P., Meyer C.A., Lockley M.G., and Lucas S.G. 1994. Archaeology, toothmarks and sauropod dinosaur taphonomy. Gaia 10:225-231.

Jacobsen A.R. 1998. Feeding behavior in carnivorous dinosaurs determined by tooth marks on dinosaur bones. Historical Biology 13:17-26.

Longrich N.R., Horner J.R., Erickson G.M., and Currie P.J. 2010. Cannibalism in Tyrannosaurus rex. PLoS ONE 5(10): e13419. doi: 10.1371/journal/pone.0013419

Matsumoto R. and Evans S.E. 2010. Choristoderes and the freshwater assemblages of Laurasia. Journal of Iberian Geology 36(2):253-274.

McLain M.A., Nelsen D., Snyder K., Griffin C.T., Siviero B., Brand L.R., and Chadwick A.V. 2018. Tyrannosaur cannibalism: a case of a tooth-traced tyrannosaurid bone in the Lance Formation (Maastrichtian), Wyoming. Palaios 33(4):164-173.

Murphy E.C., Hoganson J.W., and Johnson K.R. 2002. Lithostratigraphy of the Hell Creek Formation in North Dakota. In: J.H. Hartman, K.R. Johnson, and D.J. Nichols (Eds.), The Hell Creek Formation and the Cretaceous-Tertiary Boundary in the Northern Great Plains: An Integrated Continental Record of the End of the Cretaceous. pp. 9-34. Geological Society of America Special Papers 361.

Noto C.R., Main D.J., and Drumheller S.K. 2012. Feeding traces and paleobiology of a Cretaceous (Cenomanian) crocodyliform: example from the Woodbine Formation of Texas. Palaios 27(2):105-115. 
393 Persons W.S. and Currie P.J. 2014. Duckbills on the run: the cursorial abilities of hadrosaurs and 394 implications for hadrosaur-avoidance strategies. In: D.A. Eberth and D.E. Evans (Eds.), 395 Hadrosaurs, pp. 449-458. Indiana University Press, Bloomington and Indianapolis.

396

397

398

399

400

401

402

403

404

405

406

407 408 409 410

411

412

413

414

415 Tanke D.H. and Currie P.J. 1998. Head-biting behavior in theropod dinosaurs: Paleopathological 416 evidence. Gaia 15:167-184. 
Figure 1

Discovery location of BMR P2007.4.1

Locality map showing the geographic location of specimen BMR P2007.4.1 in Carter County, Montana.

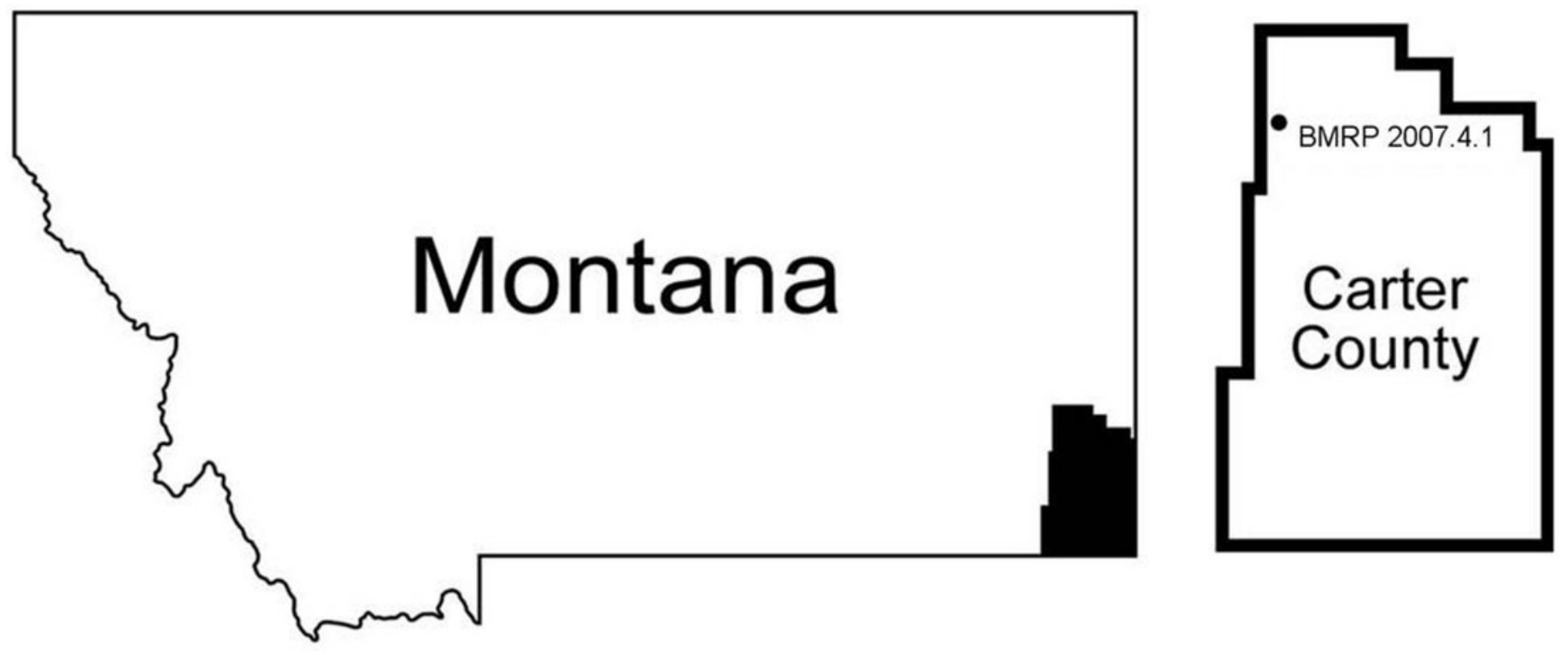


Figure 2

Stratigraphic column of the "Constantine" Quarry.

Stratigraphy of the BMR P2007.4.1 "Constantine" Quarry. 


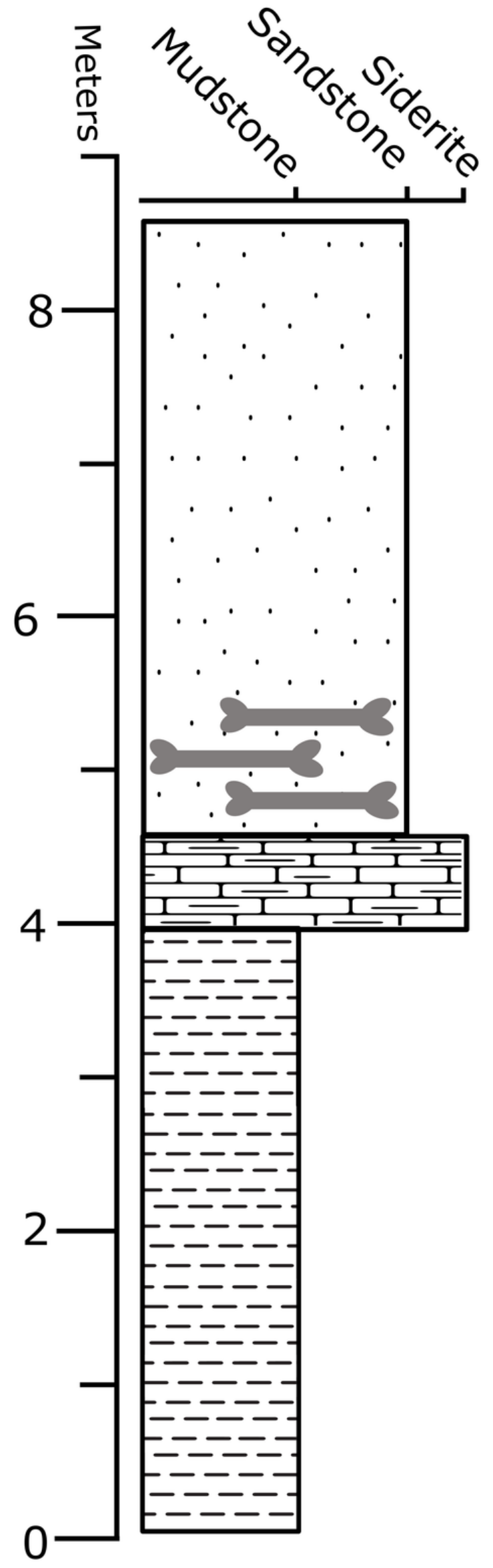


Figure 3

Map of the BMR P2007.4.1 "Constantine" Quarry.

Dorsal vertebrae (field numbers CON-2007-010, CON-2007-011, and CON-2007-012) were too weathered for collection, though their relative locations were mapped. Note the relative association of dorsal and caudal vertebrae, and pelvic elements.

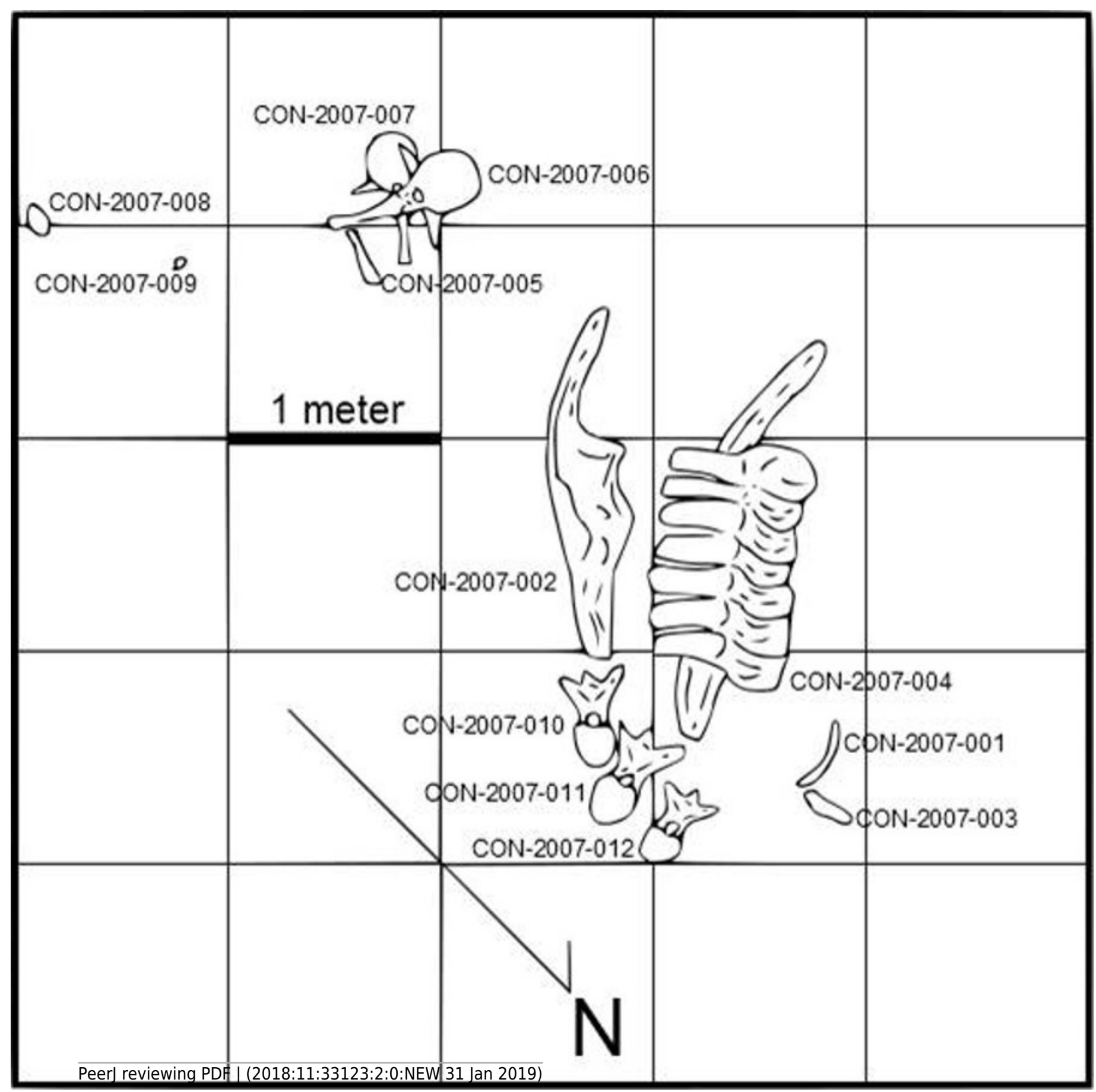


Figure 4

Punctured caudal vertebra of BMR P2007.4.1.

BMR P2007.4.1 in anterior (A) posterior (B) and ventral (C), including the two elliptical punctures on the ventral surface of the centrum $(D, E)$.

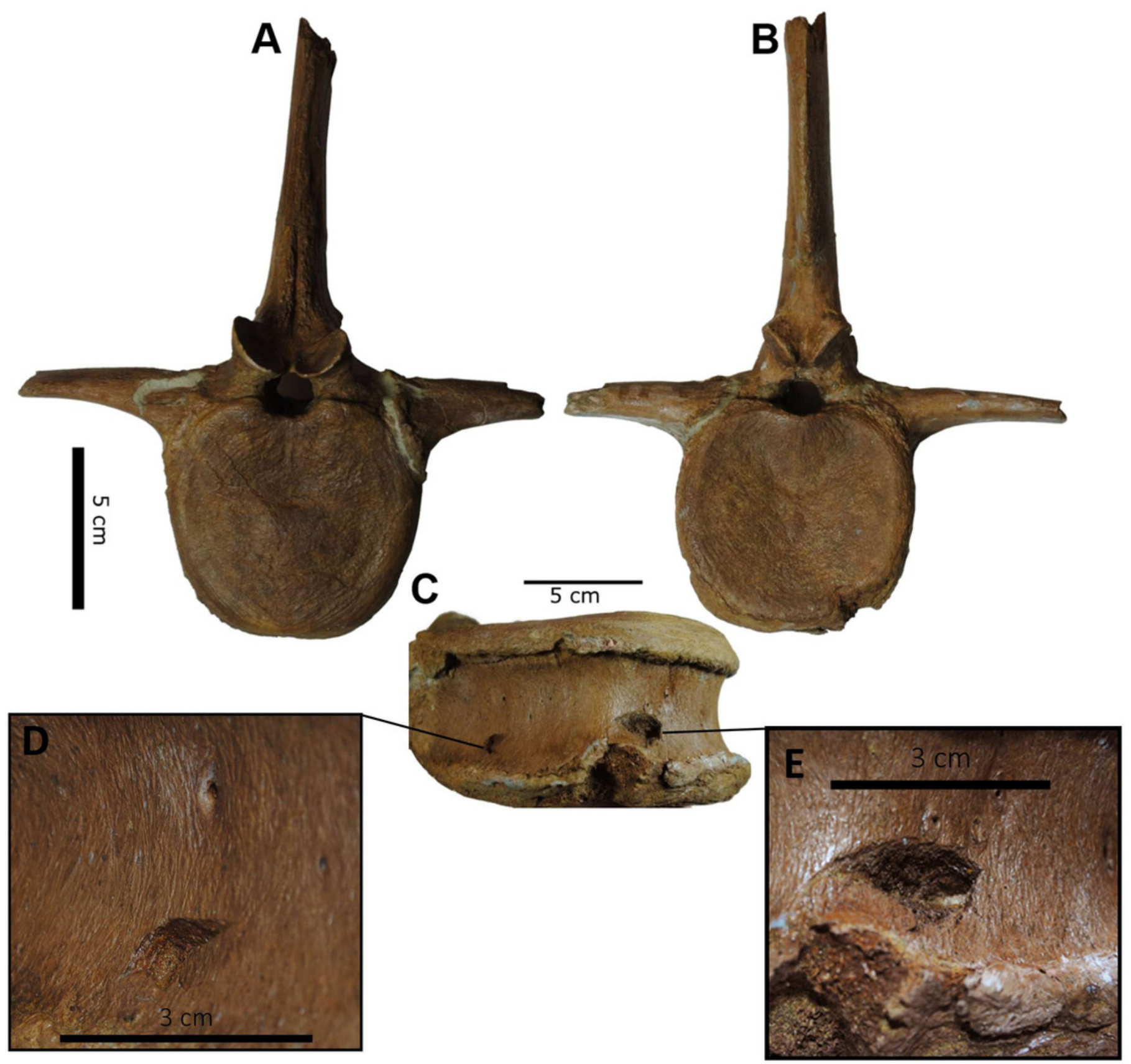




\section{Figure 5}

Silicone peel produced from BMR P2007.4.1.

Silicone peel produced from the ventral surface of the punctured caudal vertebra of BMR P2007.4.1 in vertical (A), and lateral (B) views. Note the traced outlines demonstrating the shape of the tooth casts.
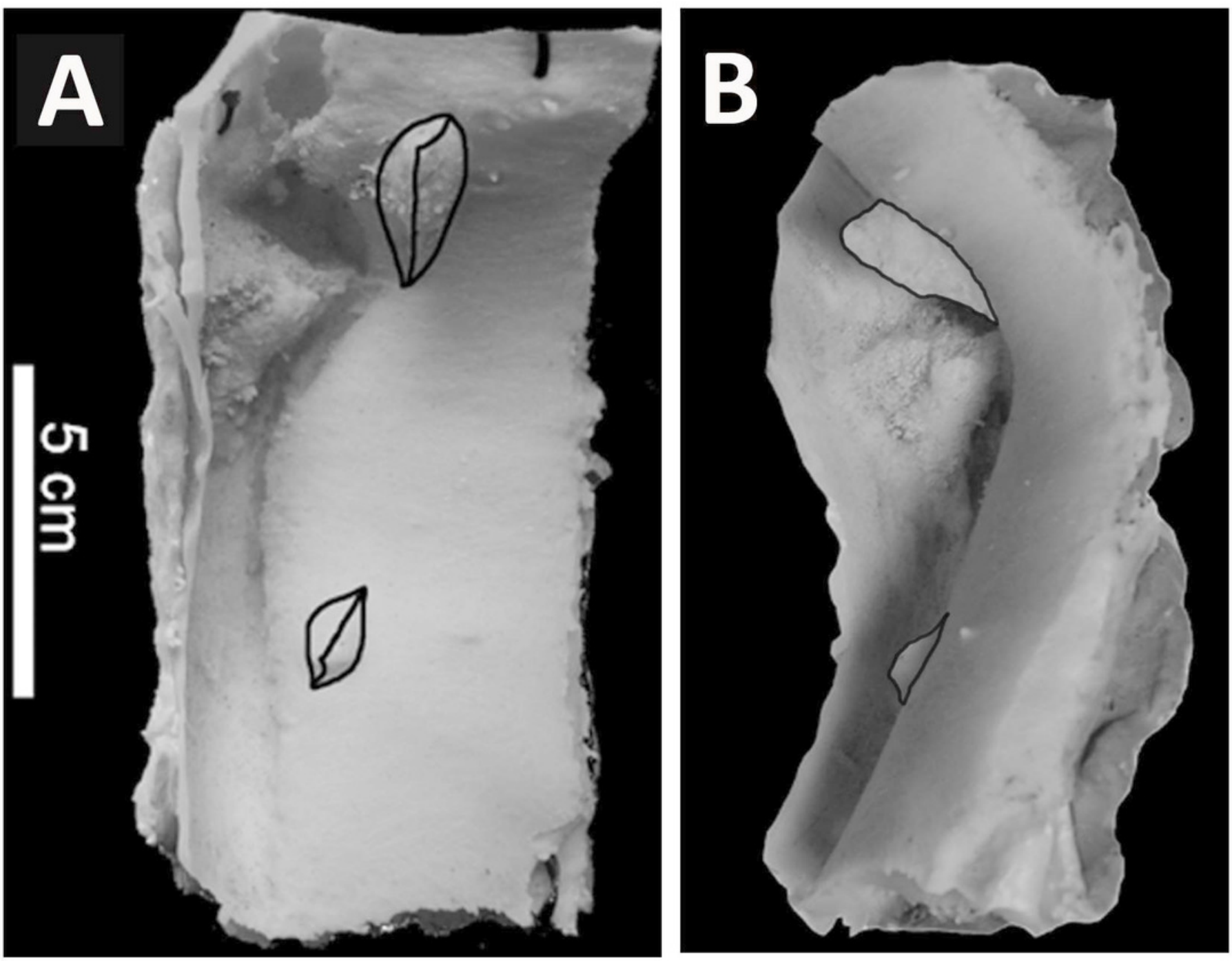
Figure 6

Casts of BMR P2002.4.1.

Casts of BMR P2002.4.1 maxilla (A) and dentary (B) to illustrate the tooth positions used for spacing measurements. Note the alternating replacement of teeth. Scale bars equal $10 \mathrm{~cm}$.

A
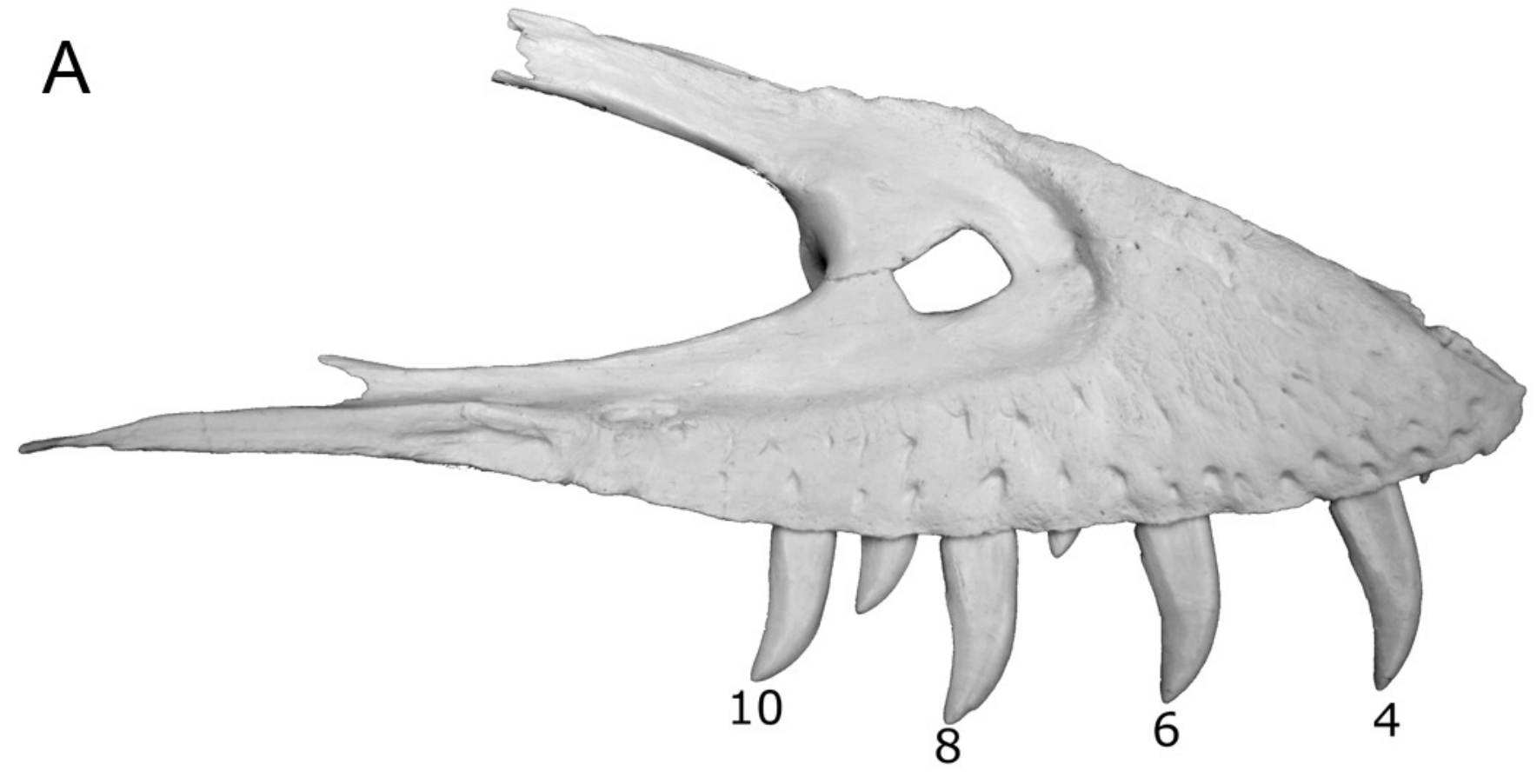

B

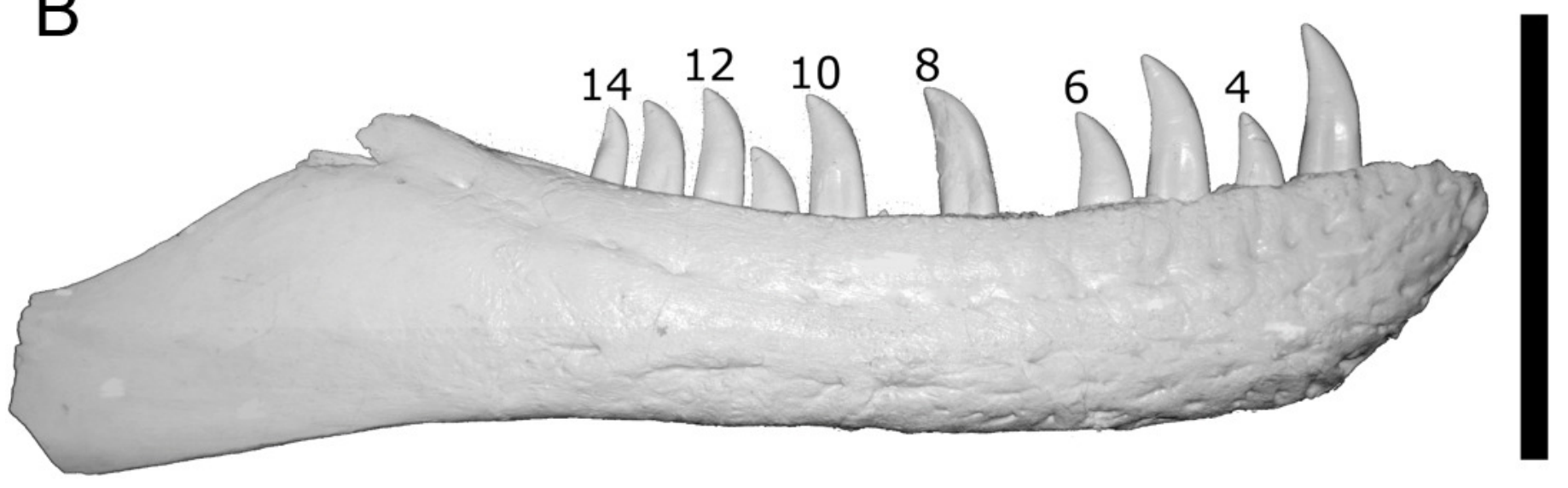


Figure 7

Maxillary and dentary measurements for BMRP 2002.4.1 and BHI 3033.

Maxillary and dentary measurements for BMRP 2002.4.1 and BHI 3033 mesiodistal and labiolingual dimensions at $5 \mathrm{~mm}$ depth compared to the bite marks on BMR P2007.4.1.

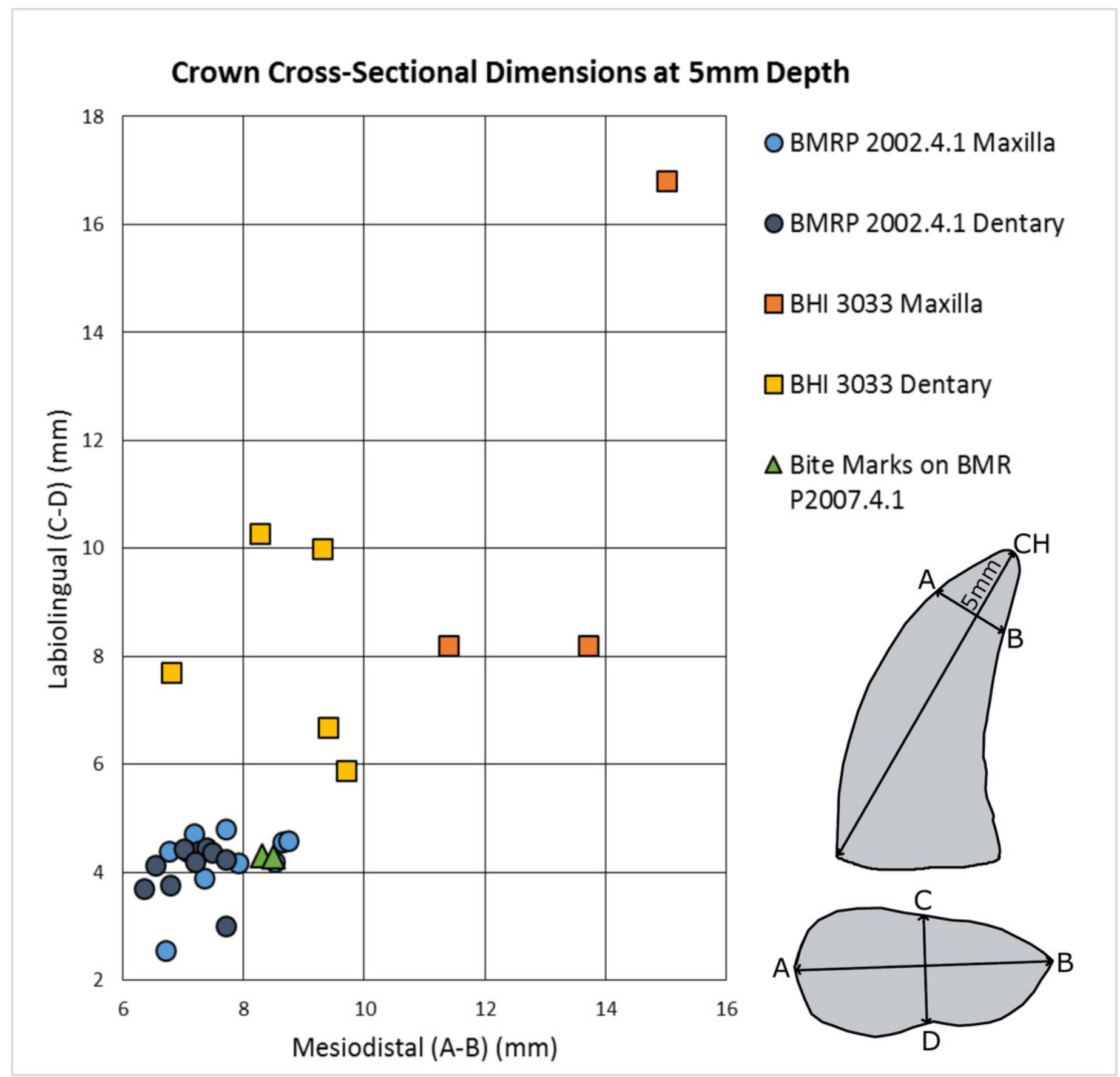




\section{Figure 8}

Digitized comparisons between tyrannosaur maxillae and BMR P2007.4.1.

Interactive manipulation of digitized NextEngine 3D scan of a cast of the right maxilla of BHI \#3033 and BMR P2007.4.1 caudal vertebra.

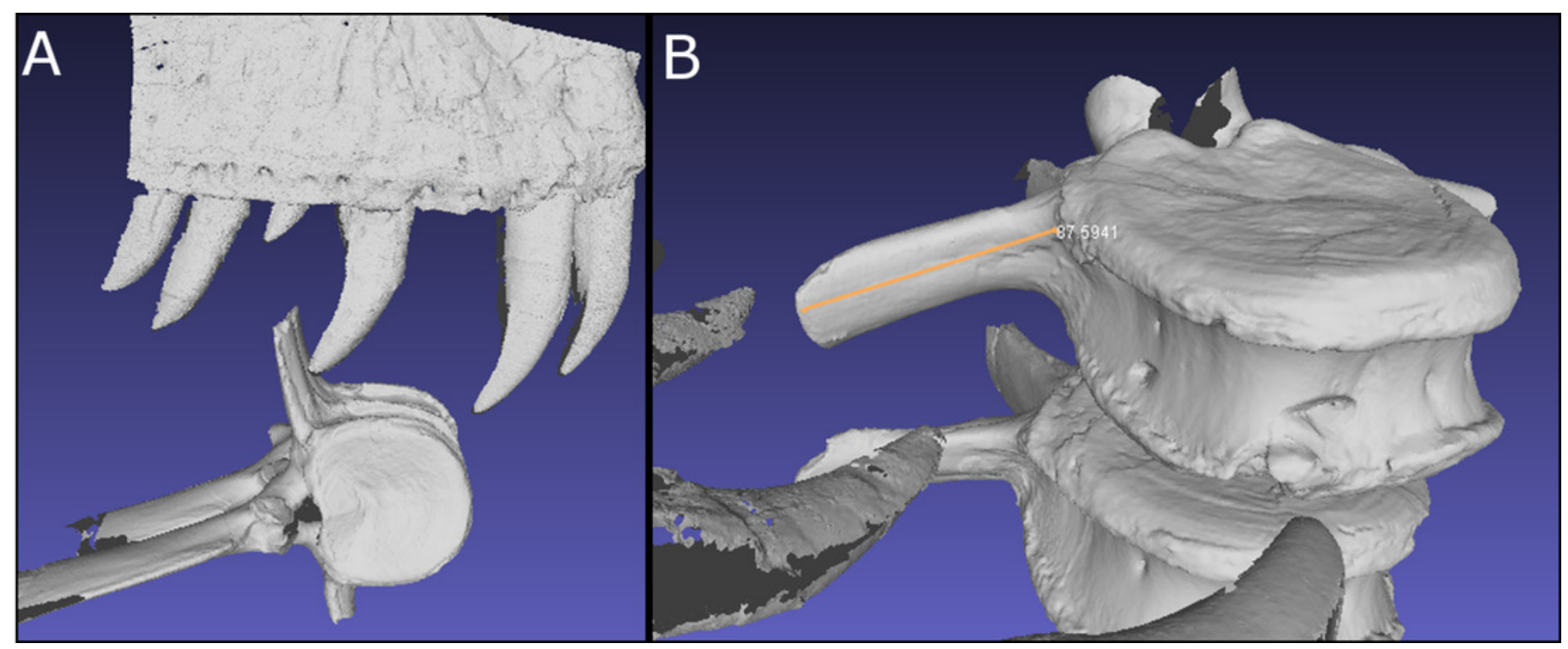




\section{Figure 9}

Digitized comparisons between BMR P2002.4.1 and BMR P2007.4.1.

Interactive manipulation of digitized NextEngine 3D scan of a cast of the right maxilla and dentary of BMR P2002.4.1, and BMR P2007.4.1 caudal vertebra.






\section{Table $\mathbf{1}$ (on next page)}

Skeletal elements from BMR P2007.4.1.

Recovered and recorded skeletal elements from the "Constantine Quarry" (BMR P2007.4.1) and taphonomic condition. 


\begin{tabular}{|l|l|l|}
\hline Field Number & Element & State/Condition \\
\hline CON-2007-001 & Rib fragment & Abraded \\
\hline CON-2007-002 & Left ilium & Heavily weathered \\
\hline CON-2007-003 & Rib fragment & Abraded \\
\hline CON-2007-004 & Sacrum and right ilium & Heavy to moderate weathering \\
\hline CON-2007-005 & Neural arch & Fractured, but mild weathering \\
\hline CON-2007-006 & Caudal vertebra & Mild weathering \\
\hline CON-2007-007 & Caudal vertebra & Mild weathering \\
\hline CON-2007-008 & Bone fragment & Heavily abraded \\
\hline CON-2007-009 & Shed Saurornithoides sp. tooth & No apparent abrasion \\
\hline CON-2007-010 & Dorsal vertebra & Heavily weathered, not collected \\
\hline CON-2007-011 & Dorsal vertebra & Heavily weathered, not collected \\
\hline CON-2007-012 & Dorsal vertebra & Heavily weathered, not collected \\
\hline
\end{tabular}




\section{Table 2(on next page)}

Measurements of tooth crowns of tyrannosaur specimens.

Mesiodistal and labiolingual measurements of teeth at $5 \mathrm{~mm}$ depth from the crown apex for A) BHI 3033, B) BMR P2002.4.1, and C) the inferred bite marks on BMR P2007.4.1. All measurements are in $\mathrm{mm}$. 
A

\begin{tabular}{|c|c|c|c|c|}
\hline \multirow{2}{*}{ BHI 3033 } & \multicolumn{2}{|c|}{ Maxilla } & \multicolumn{2}{c|}{ Dentary } \\
\hline & Mesiodistal & Labiolingual & Mesiodistal & Labiolingual \\
\cline { 2 - 5 } & 15 & 16.8 & 9.3 & 10.0 \\
\hline 11.4 & 8.2 & 8.27 & 10.27 \\
\hline 13.7 & 8.2 & 6.8 & 7.7 \\
\cline { 2 - 5 } & & 9.4 & 6.7 \\
\cline { 3 - 5 } & & 9.7 & 5.9 \\
\hline
\end{tabular}

B

\begin{tabular}{|c|c|c|c|c|}
\hline \multirow[t]{2}{*}{ BMR P2002.4.1 } & \multicolumn{2}{|c|}{ Maxilla } & \multicolumn{2}{|c|}{ Dentary } \\
\hline & Mesiodistal & Labiolingual & Mesiodistal & Labiolingual \\
\hline & 6.77 & 4.4 & 7.06 & 4.39 \\
\hline & 7.18 & 4.73 & 6.54 & 4.14 \\
\hline & 7.35 & 3.9 & 6.78 & 3.77 \\
\hline & 8.64 & 4.57 & 7.25 & 4.39 \\
\hline & 7.91 & 4.19 & 7.39 & 4.47 \\
\hline & 7.7 & 4.8 & 7.48 & 4.37 \\
\hline & 8.74 & 4.59 & 7.0 & 4.44 \\
\hline & 8.52 & 4.21 & 7.7 & 4.24 \\
\hline & 6.71 & 2.56 & 7.19 & 4.2 \\
\hline & & & 6.34 & 3.7 \\
\hline & & & 7.7 & 3.01 \\
\hline
\end{tabular}

C

\begin{tabular}{|l|l|l|}
\hline BMR P2007.4.1 “Bite Marks” & Mesiodistal & Labiolingual \\
\hline & 8.3 & 4.31 \\
\cline { 2 - 3 } & 8.5 & 4.3 \\
\cline { 2 - 3 }
\end{tabular}




\section{Table 3(on next page)}

Measurements of crown spacing in tyrannosaur specimens.

Tooth crown spacing between maxillary (A) and dentary (B) teeth in the juvenile tyrannosaur BMR P2002.4.1. All measurements are in $\mathrm{mm}$. 


1 A
\begin{tabular}{|c|c|}
\hline Crown Spacing & Maxillary (mm) \\
\hline $4-6$ & 70.2 \\
\hline $6-8$ & 73.3 \\
\hline $8-10$ & 62.8 \\
\hline B Average & 68.7 \\
\hline \multicolumn{3}{|c|}{} \\
\hline Crown Spacing & Dentary(mm) \\
\hline $4-6$ & 53.3 \\
\hline $6-8$ & 49.8 \\
\hline $8-10$ & 39.2 \\
\hline $10-12$ & 33.7 \\
\hline $12-14$ & 33 \\
\hline Average & 41.8 \\
\hline
\end{tabular}

4 